\title{
Preliminary Magnetic Susceptibility Results from the Northwestern Part of Madinah, Saudi Arabia: Environmental Degradation of Wadi Aqiq
}

\author{
Haider Zaman*, Adnan Aqeel \\ Department of Geology, Faculty of Science, Taibah University, Madinah, Saudi Arabia \\ Email: ‘hhzaman@taibahu.edu.sa,haider_zaman61@hotmail.com
}

How to cite this paper: Zaman, H. and Aqeel, A. (2018) Preliminary Magnetic Susceptibility Results from the Northwestern Part of Madinah, Saudi Arabia: Environmental Degradation of Wadi Aqiq. Open Journal of Geology, 8, 446-462. https://doi.org/10.4236/ojg.2018.84026

Received: February 26, 2018

Accepted: April 25, 2018

Published: April 28, 2018

Copyright (c) 2018 by authors and Scientific Research Publishing Inc. This work is licensed under the Creative Commons Attribution International License (CC BY 4.0).

http://creativecommons.org/licenses/by/4.0/

\section{(c) (i) Open Access}

\begin{abstract}
Recent advances in environmental magnetism have led to new applications in understanding soil pollutions from anthropogenic sources. The utility of environmental magnetic techniques varies widely depending on biological, chemical and physical processes that create and transform soils and sediments. Researchers in some European and Asian countries have successfully studied heavy metals in top soils using magnetic susceptibility technique. Accelerated urbanization in the past two decades has significantly altered the environmental landscape of Madinah. A famous wadi Aqiq in the heart of Madinah, an important conduit for groundwater recharge, is one of the most affected. This study thus focuses on magnetic susceptibility application as environmental magnetic technique to map heavy metal concentrations in top soils along wadi Aqiq, northwestern part of Madinah. Higher values of magnetic susceptibility from soil cover than those from parent igneous rocks indicate anthropogenic origin metallic contamination in the study area. The trucks/tankers parking area reveal highest values of magnetic susceptibility. The areas close to heavy vehicular traffic along two major roads also indicate higher magnetic susceptibilities because of enhanced metallic contaminations. The areas covered by residential and commercial buildings reveal medium level of magnetic susceptibilities. The left over asphalted materials at various places in the area is another source of high magnetic susceptibilities. Widely distributed metallic objects in the area, such as hangers, cans, and construction materials also contribute to enhanced soil contamination as evident from high magnetic susceptibilities.
\end{abstract}

\section{Keywords}

Anthropogenic Sources, Northwestern Madinah, Vehicular Traffic, Magnetic Susceptibility, Metallic Contamination 


\section{Introduction}

Magnetic susceptibility technique is a fast and useful tool to identify anthropogenic emissions, estimate heavy metal concentrations and to detect sources of pollutions. Preliminary susceptibility survey of polluted area generally provide a step forward to more expensive investigations, such as detailed magnetic, mineralogical or geochemical analyses. Factors other than anthropogenic also contribute to pollutions in top soils. The sources of non-anthropogenic magnetic susceptibility can be: 1) the lithology of the parent material (bedrock), producing sand-sized magnetite and clay-sized maghemite, 2) the microbial and bacterial activities that bring initial dissolution of non-magnetic iron oxides and a subsequent production of secondary ferrimagnetic minerals, causing magnetic susceptibility increase in top soils [1]. The microcrystalline maghemite or magnetite formed by such processes is thus pedogenic in origin. Magnetic susceptibility variations in soils also depend on: a) grain size distribution; smaller grains $(<50$ $\mathrm{nm}$ ) cause an increase in magnetic susceptibility; b) chemical processes, such as alternating cycles of oxidation-reduction, may cause susceptibility increase in well-aerated top soils; c) biogeochemical or translocation processes [2] [3] [4].

Anthropogenic contribution of heavy metals is, however, a predominant factor for magnetic susceptibility in the organic layers of top soils. Iron oxides related anthropogenic particles, originating from high-temperature combustion of fossil fuels, cause a significant enhancement in topsoil magnetic susceptibility [5] [6] [7]. Another researcher have reported that cubic structure of magnetite can incorporate various toxic elements of heavy metals (such as $\mathrm{Cd}, \mathrm{Cr}, \mathrm{Ni}, \mathrm{Pb}$ ) and other organic contaminants [8]. Researchers have also found industrially produced magnetite (associated with such elements) in fly ashes, vehicles emissions, and in dusts from industries/open-pit mining [7] [9] [10]. According to them, fly ashes are potentially the most significant source of anthropogenic ferrimagnetics in the upper soil horizons.

Magnetic susceptibility surveys have been widely used as a cost-effective technique to document spatial distributions of magnetic parameters from anthropogenic pollutants [11]-[24]. Different areas of Madinah city are experiencing a fast track environmental degradation from vehicular traffic, uncontrolled waste dumping and agricultural activities. Because of the usefulness of magnetic susceptibility technique in identifying environmental pollutions, preliminary survey were conducted along seven kilometers long profiles in the northwestern part of Madinah (Figure 1 and Figure 2). The aim behind this survey is to document the effects of human instigated metallic pollutions in one of the main groundwater recharge areas of Madinah city.

\section{Location, Climate, Geology and Hydrogeology of the Area}

The holy city of Madinah is located in the western part of the Arabian Shield. The study area is located on the western bank of wadi Aqiq, northwestern part of Madinah (Figure 2). The Prince Naif Road (also called the University Road) 


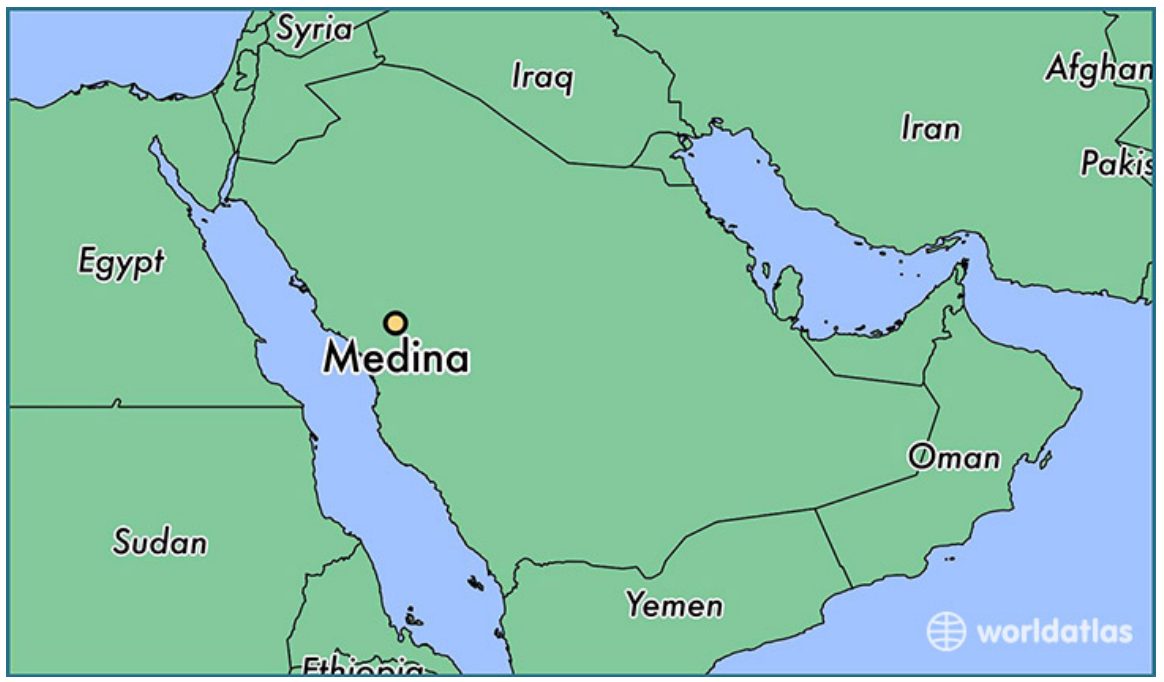

Figure 1. Location map of Saudi Arabia with respect to other countries in the region (from world atlas). Location of Madinah is marked by a circle.

bound the area to the west and a north-south directed Al-Ayun road across wadi Aqiq bound the area to the east. Administratively, the study area is a part of Al-Barakah District (locally named as Al-Jurf), bounded to the east by Al-Ayun district and to the west by Az-Zahrah district. Several small hills of igneous rocks crop out in the area. Agricultural fields and a mix of residential/commercial properties represent about $60 \%$ and $40 \%$ of the study area, respectively. Commercial properties in the area include restaurants, groceries stores, and vehicular workshops.

Climatically, the study area is located in the arid zone. The maximum summer temperature sometime reaches up to $48^{\circ} \mathrm{C}$ and the minimum winter temperature drop down up to $2^{\circ} \mathrm{C}$. The maximum annual rainfall (in winter) reaches up to 17 $\mathrm{mm}$. Topographically the city of Madinah is built on a nearly flat basin, surrounded by lava plateaus and low to medium altitude hills/mountains (Jabal in Arabic). The most famous among these mountains are Jabal Uhud in the north and Jabal Ayre in the southwest. Surface elevation in the city area is $600-610$ meters above mean sea level. Mountains and hills in the area have elevations between 900 and 1100 meters above mean sea level. The oldest rocks in Madinah (Upper Proterozoic) have two main groups [25]. The Uraifi Formation represents the Al-Ayse Group, while the Qidirah and Dawnak formations represent the overlying Furayh Group. Epiclastic and interbedded silicic volcanic rocks are the main components of the Urayfi Formation (mainly exposed in the north and northeast). Gabbroic rocks intrude these volcanics at some places (e.g., Jabal Sela area). The Qidirah Formation is volcanic in origin (andesite and basalt), outcropping as small hills in the southwestern part of Madinah city. The Dawnak Formation is detrital in origin (such as sandstone, conglomerates, siltstone, tuff and marble), outcropping in the southern part of Madinah (e.g., Jabal Ayre). Granitic rocks intrude the Furyah Group in the west and northwest. The Tertiary and Quaternary age lava plateaus surround the city from east, south 

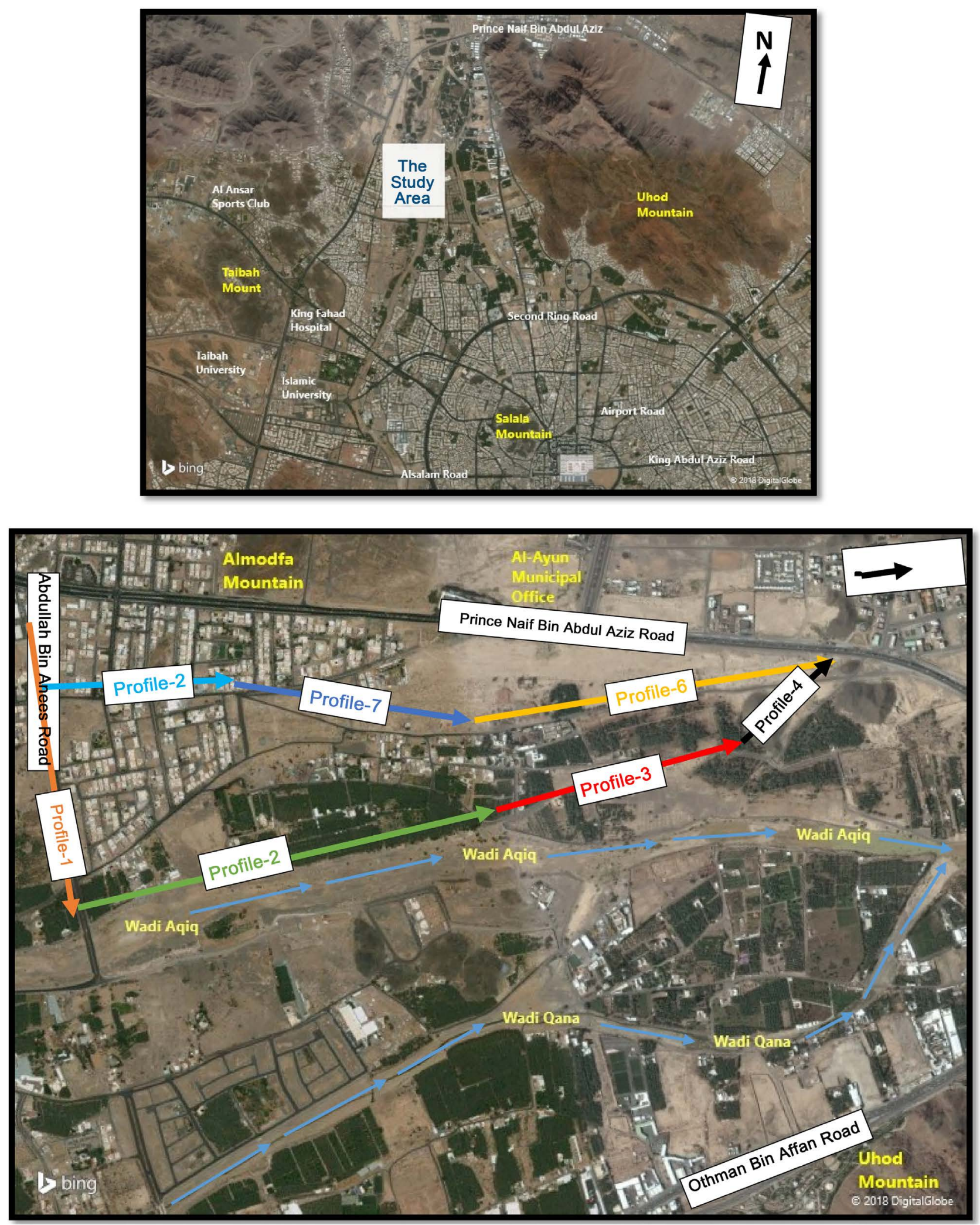

Figure 2. Topographic maps of the study area (modified from Google Earth). The top map shows location of the study area with respect to central Madinah. This map show half of Madinah city towards north. The famous Uhud Mountain is located to the east of the study area across wadi Aqiq. The bottom map shows the study area locally with respect to main Prince Naif Road in the west and wadi Aqiq in the east. The measured profiles (1 - 7) are marked by different colors in this map. 
and west.

Two major drainage outlets (wadis) border the city of Madinah. The wadi Aqiq flows northward in the western part and is joined by wadi Qana from the east. In the surrounding basaltic plateaus, the drainage pattern is still in the early stage of development, and only a few shallow intermittent wadis exist. Surficial deposits such as eluvial, sabkhah, khabra and wadi deposits cover the study area along Wadi Aqiq. The head of wadi Aqiq is about $150 \mathrm{~km}$ south of Madinah city [25]. It carries water for a few days after the rainfall, but quickly lost through direct infiltration and evaporation [26]. Based on the lithological characteristics and hydraulic behavior, the water aquifers in the area have been classified into two types, i.e., continuous and discontinuous [26] [27] [28]. Most of the groundwater wells are located in the basaltic aquifer to the east of wadi Aqiq. Water table in the area ranges from 50 to 80 meters below the surface.

\section{Methodology and Field Procedure}

Magnetic susceptibility measures the magnetizability of a material. In natural environment, magnetizability tells us about the minerals (particularly Fe-bearing minerals) present in soils, rocks, dusts and sediments. Therefore, the magnetic susceptibility measurements can provide useful information similar to that produced by other mineralogical techniques. For in-situ surface measurements in the study area, the MS2 Magnetic Susceptibility Meter (Bartington, UK) in conjunction with the $M S 2 D$ loop probe is used. The image in Figure 3 shows magnetic susceptibility measurements in the field with MS2D loop probe. A well-exposed soil cover along the studied profiles was the reason to choose this

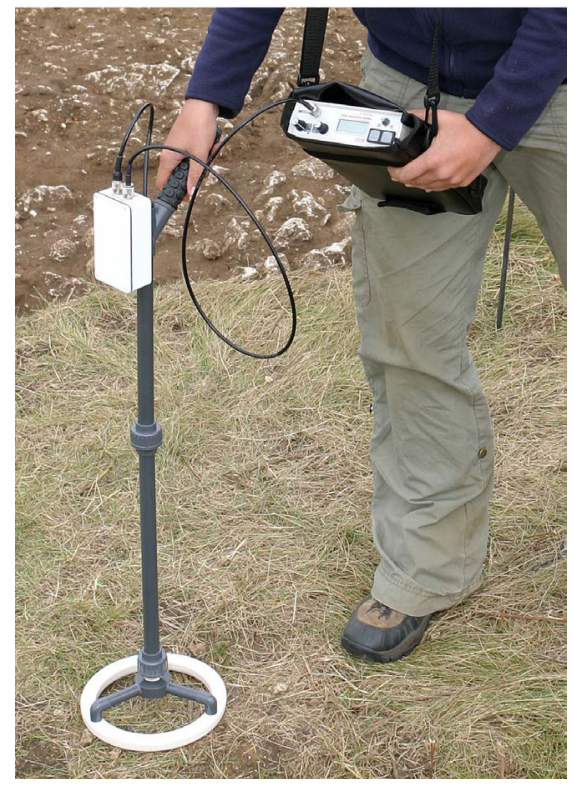

Figure 3. Magnetic susceptibility measurements in the field using MS2D loop probe. This image is taken from the operation manual of MS2 Magnetic Susceptibility system (Bartington Company, UK). 
probe for magnetic susceptibility measurements. The MS2D loop probe is a field sensor, $185 \mathrm{~mm}$ in diameter, designed to make surface measurements of soils, rocks, and stream channels. The main part of the magnetic susceptibility measurement kit is a coil. The coil when connected to a source of alternating voltage produces an alternating magnetic field. If material is in the reach of the magnetic field produced by the coil, its frequency changes. The top 60 to $100 \mathrm{~mm}$ of the land surface is in the effective range of the coil.

To document magnetic minerals concentrations in top soils of the study area, we conducted preliminary magnetic susceptibility surveys along seven profiles. The available roads network provided an opportunity to do survey along the profiles. The first profile, about 1100 meters long, follows the Abdullah Bin Anees Road. This road connects the main Prince Naif Road in the west to wadi Aqiq Bridge in the east. The area is a mix of residential/commercial properties and agricultural fields. The second profile starts at wadi Aqiq Bridge, and extend up to 1375 meters towards north on un-asphalted valley road. This profile has agricultural fields to the west and wadi Aqiq to the east. The third profile of 1200 meters follows a narrow asphalted street (Abdul Samad Street) from south to north at some distance from wadi Aqiq. Most part of this profile passes through the agriculture fields with some isolated residential buildings. The fourth profile, about 350 meters long, cover a narrow track road between an igneous hill in the east and the main Prince Naif Road in the west. The fifth profile passes through the residential and commercial areas along 650 meters long Aamer Bin Salamah Street (south to north). The sixth profile, about 850 meters long, follow a narrow south-north directed Yazid Abn Abi Street in a mix agricultural, residential and open fields areas. The seventh profile follows the same road for 1250 meters before joining the main Prince Naif Road obliquely. About 269 stations, at 25 meters distance from each other, are measured. The surveyed profiles cover about seven kilometers track between the main Prince Naif Road in the west and wadi Aqiq in the east.

\section{Results}

\subsection{Profile-1: Abdullah Bin Anees Road}

This profile passes through a mix of residential, commercial (mostly vehicular workshops) agriculture properties (Figure 2). Magnetic susceptibility graph (Figure 4) indicates some high peaks in the trucks and tankers parking area. Most of the remaining magnetic susceptibility readings along this profile are less than $4 \times 10^{-3}$ (SI), but still moderate to high in range. The left over asphalted materials in open field (across a petrol station) show relatively higher values of susceptibility. This may be due to basaltic origin gravels used in the mixture. The highest peak of $12 \times 10^{-2}$ (SI) is probably due to hidden metallic objects in top soils. Metallic objects, such as cloth hangers, soft drink cans, and metallic pieces of building materials are widely distributed in the area without any discrimination. Overall, factors like car workshops, tankers parking, improper waste 


\section{Profile-1: Magnetic susceptibility variation along} Abdullah Bin Anees Road

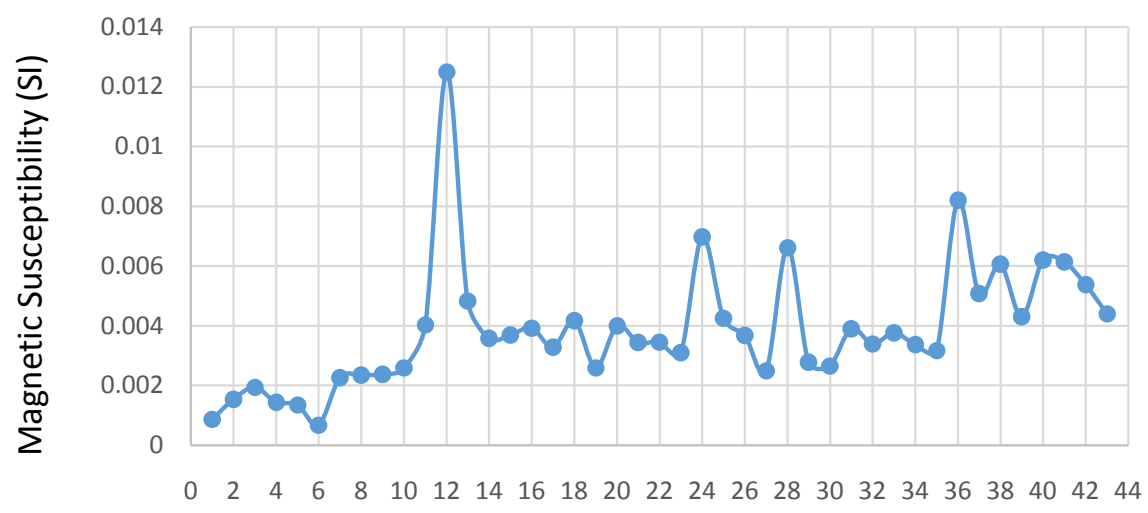

Distance Between Each Station (25 Meters)

Figure 4. Magnetic susceptibility variation along Abdullah Bin Anees Road. This profile connect wadi Aqiq Bridge in the east with Prince Naif Road in the west. This graph indicate highest value $\left(12 \times 10^{-2} \mathrm{SI}\right)$ in the trucks and tankers parking area, which may be due to hidden metallic objects in soils. All other stations along this profile reveal magnetic susceptibility values up to $4 \times 10^{-3}(\mathrm{SI})$.

dumping and heavy vehicular traffics are causing enhancement in magnetic contaminations along this profile. Unfortunately, these contaminants easily find their way in to wadi Aqiq, the main water recharge area in Madinah.

\subsection{Profile-2: Un-Asphalted Track Road along Wadi Aqiq}

As shown in Figure 5, most of the magnetic susceptibility readings along this profile are between 4 and $5 \times 10^{-3}$ (SI). However, few stations give relatively higher values as well. The highest peaks at three stations $(28,41$ and 46$)$ are due to hidden metallic objects thrown with other waste materials in to wadi Aqiq. The first two stations have relatively high values as well, which may be due to their proximity to main Abdullah Bin Anees Road. Heavy traffics on busy roads usually cause an enhanced metallic contamination. Unfortunately, the owners of the residential and agriculture properties in the area use wadi Aqiq as a dumping ground for a variety of waste materials. The rusted and decomposed forms of these metallic and non-metallic materials eventually find their ways in to the aquifer system under wadi Aqiq.

\subsection{Profile-3: Abdul Samad bin Al-Fadl Street}

As shown in Figure 6, most stations along this profile have magnetic susceptibility values of less than $4 \times 10^{-3}$ (SI). However, some of the stations (18- 22 and 34 - 36) reveal relatively higher values as well. Higher susceptibility values at stations 18 - 22 are at small residential village, ascribing their origin to anthropogenic activities. Higher values at stations $34-36$ are due to dark colour asphalted materials dumped along the road. According to our observations, magnetic susceptibilities of fine-grained sediments are higher than that of coarse-grained, 
Profile-2: Magnetic Susceptibility Variation Along Wadi Aqiq (South-North)

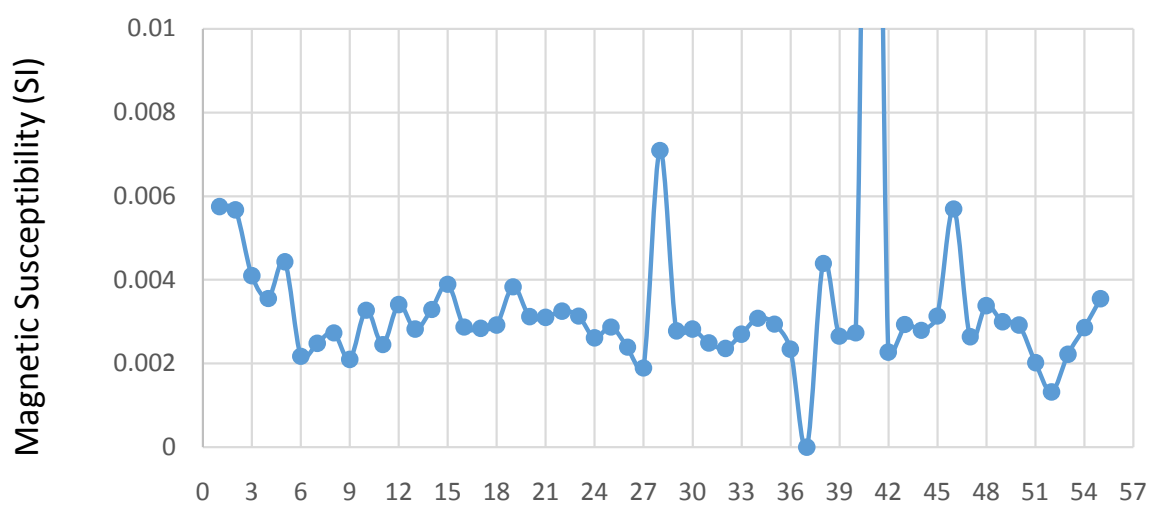

Distance Between Each Station (25 Meters)

Figure 5. Magnetic susceptibility variation along wadi Aqiq. This profile extend 1375 meters from wadi Aqiq Bridge towards north. Except few stations with very high susceptibility values, most of the readings remain between 4 and $5 \times 10^{-3}(\mathrm{SI})$.

\section{Profile 3: Magnetic Susceptibility Variation Along Abdus Samad Bin Al-Fadl Street (South-North)}

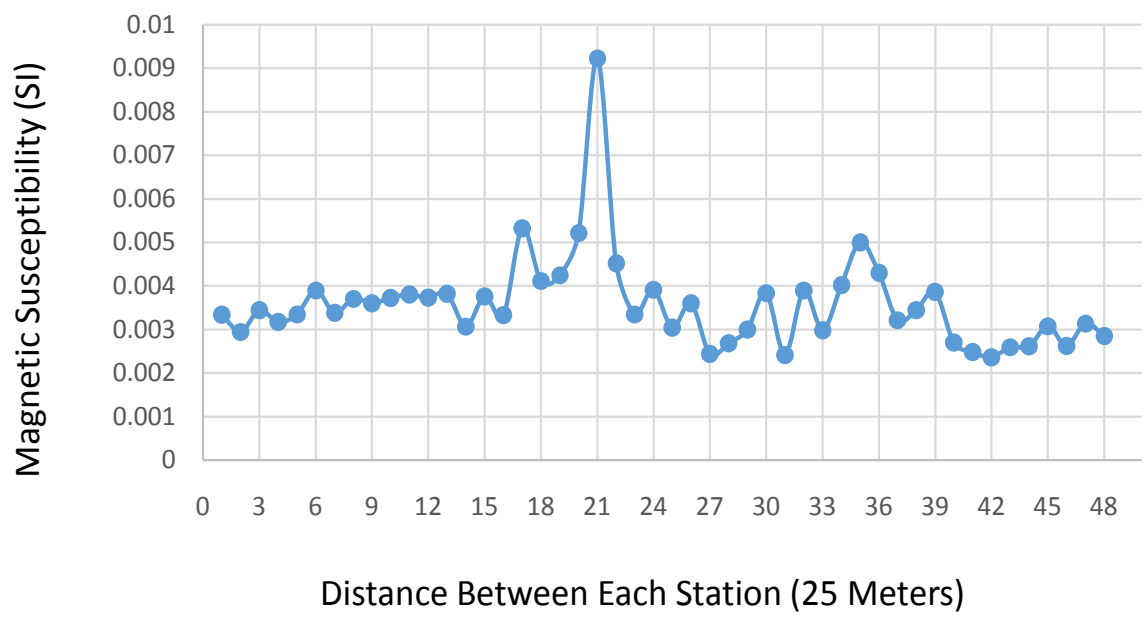

Figure 6. Magnetic susceptibility variation along Abdus Samad Bin Al-Fadl Street. The highest observed values (stations 18 - 22) are from a small residential village. Most of the remaining stations have magnetic susceptibility values up to $4 \times 10^{-3}$ (SI).

indicating the presence of superparamagnetic grains in the earlier case. Observations of low magnetic susceptibilities along narrow farms road indicate less contamination from vehicular traffics.

\subsection{Profile-4: Igneous Hill to Prince Naif Road (NE-SW Directed)}

This short profile of 14 stations follows a narrow road on the way to main Prince Naif Road. Most magnetic susceptibility readings up to station 10 (except station 6 ) remain under the threshold value of $3 \times 10^{-3}$ SI (Figure 7). Relatively higher 
Profile-4: Magnetic Susceptibility Variation Along Narrow Road From Igneous Hill to Prince Naif Road

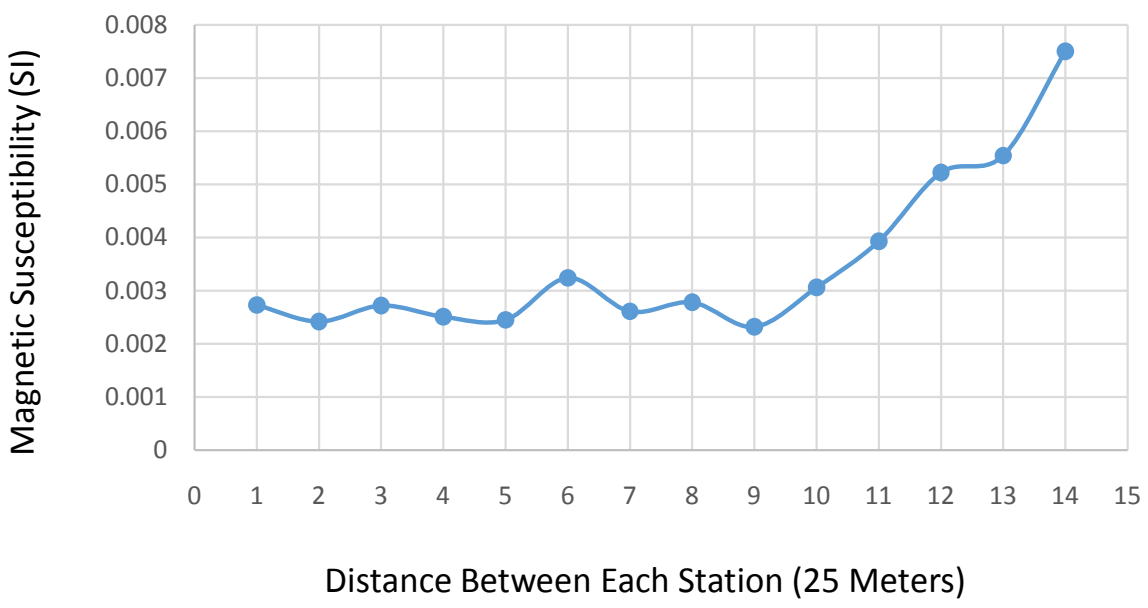

Figure 7. Magnetic susceptibility variation along a narrow road, connecting an igneous hill to main Prince Naif Road. Most readings up to station-10 remain under the threshold value of $3 \times 10^{-3}$ (SI). However, a significant rise in magnetic susceptibility is observed when getting close to the main road, which we attribute to heavy vehicular traffic.

value of susceptibility at station 6 is probably due to anthropogenic contaminations on a gate to farmhouse. Interesting to note is a significant rise in magnetic susceptibility when getting closer to the main Prince Naif Road. These high values after station 10 are probably due to heavy vehicular traffic on the main road. As mentioned in the literature, roadsides in busy urban environment usually get pollution from particulate matter derived from vehicle exhaust, tyres abrasion, and combustion emissions [29] [30].

\subsection{Profile-5: Aamer Bin Salamah Road}

This profile passes through the residential and commercial areas. Magnetic susceptibility values from this profile are relatively higher (Figure 8 ) than those from profiles 2, 3 and 4 . About $60 \%$ of the stations reveal susceptibility values higher than $4 \times 10^{-3}$ (SI). A maximum value observed at station-1 is due to rusted metallic objects in the soils. Dark colour fine-grained soils in front of a petrol station and near the residential gates/parkways also reveal higher values. This trend indicates an increasing level of metallic contaminations in the areas frequently used by human. An un-controlled dumping in the open plots is another matter of concern, causing severe pollution in the area.

\subsection{Profile-6: Yazid Abn Abi Road (South Section)}

Except few residential facilities, this profile mostly passes through the open field area. The observed magnetic susceptibilities up to station-13 remain under the threshold value of $4 \times 10^{-3}$ SI (Figure 9). Light vehicular traffic and sparse population are causing relatively low susceptibility values along this part of the profile. The trend, however, changes when residential properties start, pushing 
Profile-5: Magnetic Susceptibility Variation Along Aamer Bin Salalmah Street (South-North)

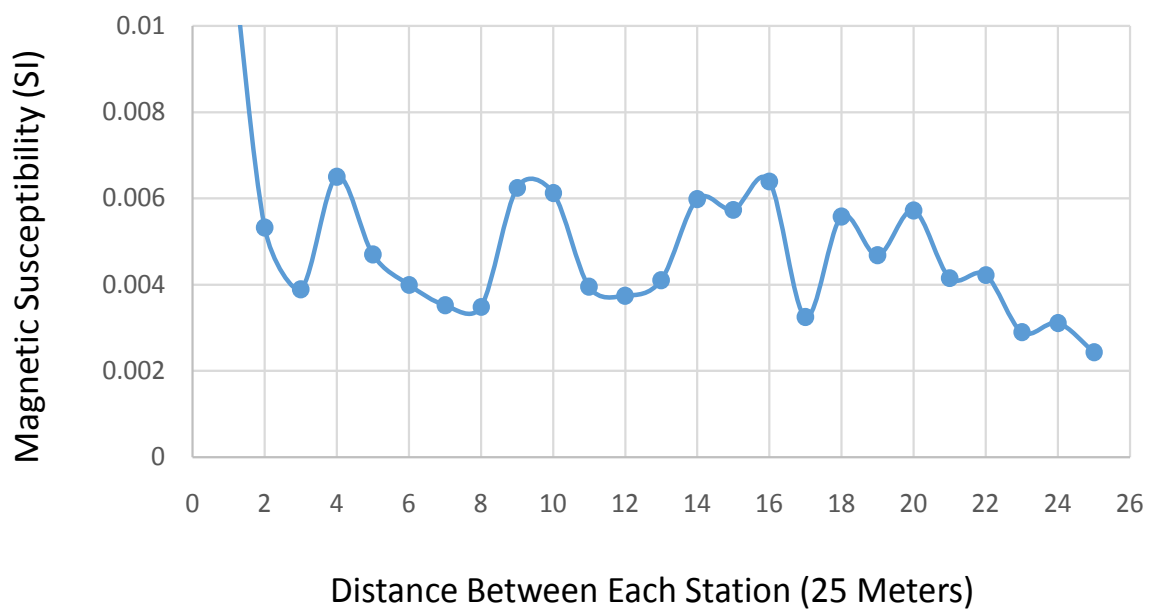

Figure 8. Magnetic susceptibility variation along Aamer Bin Salalmah Street from south to north. Because of dense residential and commercial facilities along this profile, the magnetic susceptibility values are relatively higher than those measured along wadi Aqiq. About $60 \%$ of the stations along this profile have susceptibility values higher than $4 \times 10^{-3}$ (SI).

\section{Profile-6: Magnetic Susceptibility Variation Along Yazid Ibn Al-Hasan Street (First Section, South-North)}

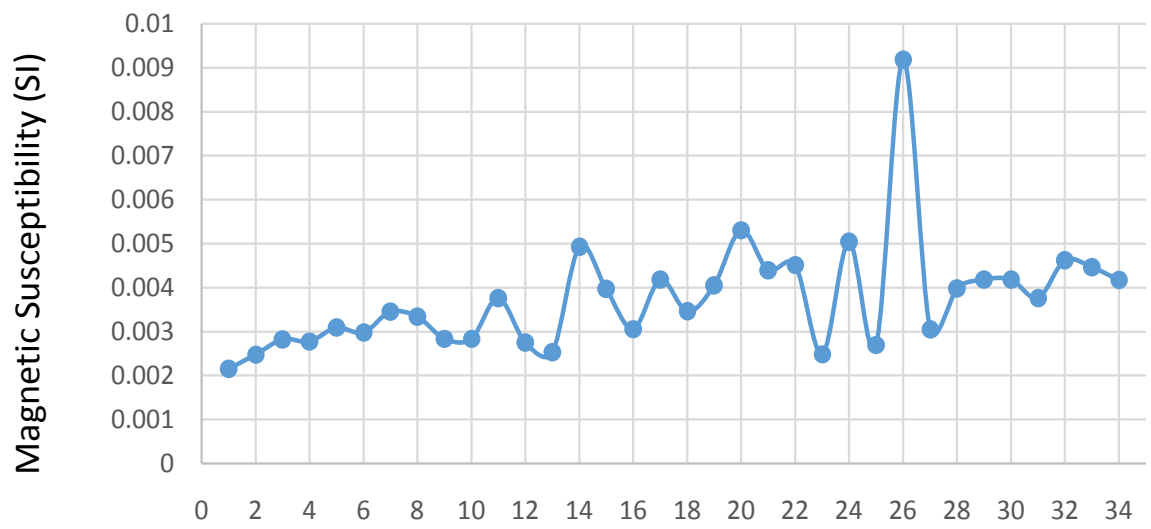

\section{Distance Between Each Station (25 Meters)}

Figures 9. Magnetic susceptibility variation along the south-north directed Yazid Ibn Al-Hasan Street (south section). Until station-13, the magnetic susceptibility values remain under the threshold value of $4 \times 10^{-3}$ (SI). Sparse residential/commercial facilities and only light vehicular traffic along this profile are the reasons for low susceptibility values. However, the trend change at the start of residential facilities, pushing magnetic susceptibility values at some stations in the excess of $5 \times 10^{-3}(\mathrm{SI})$.

magnetic susceptibility values at some stations over $5 \times 10^{-3}(\mathrm{SI})$. A construction company is currently utilizing an open ground opposite to the residential village as a storage facility for heavy pipes and machinery. This facility is probably causing metallic contaminations and an eventual environmental degradation in the area. 


\subsection{Profile-7: Yazid Abn Abi Road (North Section)}

About $80 \%$ of this profile is passing through the agricultural area, and remaining $20 \%$ in the residential area. Highest values of magnetic susceptibility $\left(>6 \times 10^{-3}\right.$ SI) along this profile is from an area where heavy metallic pipes and machinery are stored (Figure 10). In general, high values of magnetic susceptibility along this profile are due to its proximity with the main Prince Naif Road. Heavy vehicular traffic on this busy road is a source of metallic pollution in the area. An enhanced level of magnetic particles is deriving from motor vehicle exhaust, tyres abrasion and combustion emissions. Basaltic origin gravels in the asphalted mixture is also a source of enhanced susceptibility at some stations along this profile. In general, anthropogenic activities are the most dominant sources of magnetic contamination/pollution along this profile.

\section{Discussion and Interpretation}

The landscape of the study area is a typical example of a wadi (valley) system. The igneous origin mountains bound this wadi from the east and west. Various small hills of igneous origin also crop out in the study area. The parent materials, originated from these igneous bodies, greatly influence the process of soil formation (pedogenesis) in the area. The contents of magnetic minerals in these rocks are usually higher than that in the sedimentary rocks. Historically, the study area remained a hub of agricultural activities. However, due to its vicinity to public hospitals and two university campuses, new residential/commercial sectors developed rapidly in the area. Because of this fast-track urbanization, soil cover in

Profile-7: Magnetic Susceptibility Variation Along Yazid Ibn Al-Hasan Street (2nd section, South-North)

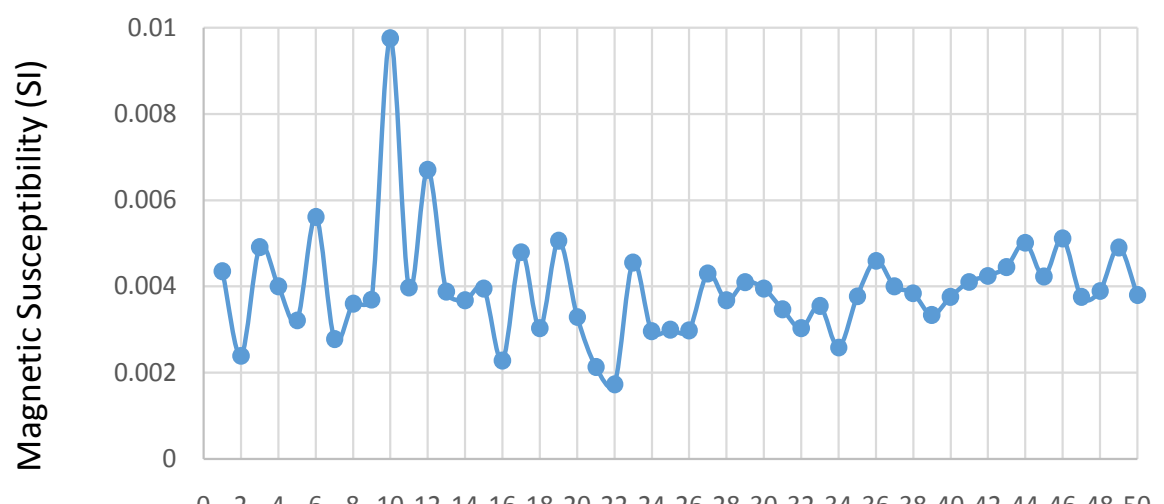

Distance Between Each Station (25 Meters)

Figure 10. Magnetic susceptibility variation along the south-north directed Yazid Ibn Al-Hasan Street (north section). The highest susceptibility values $\left(>6 \times 10^{-3} \mathrm{SI}\right)$ along this profile is recorded near the storage facility for heavy metallic objects (pipes and machinery). In general, high values of magnetic susceptibility along this profile are due to its proximity to busy Prince Naif Road. 
the area received significant amount of contaminations from increasing anthropogenic activities. These contaminations appeared in the shape of higher ferrimagnetic concentrations, as evident from high magnetic susceptibilities. Because of low rainfall in the region, these fine-grained ferrimagnetic particles stay in top soils for relatively longer time than those in high rainfall regions. However, high wind in the area transport them in to low-lying areas of wadi Aqiq.

The novelty of this study resides in a fact that no such study is conducted in this part of Saudi Arabia before. This study indicates several anthropogenic activities responsible for high metallic contaminations in the main water recharge area. The most noticeable among them is the improper waste dumping (i.e., building materials and residential waste) in the open plots and in the low-lying areas of wadi Aqiq. This study, thus, provides an important clue to managers of the city municipality to act against such unlawful hazardous activities.

\subsection{Distribution of Magnetic Susceptibility in the Study Area}

Figures 4-10 show variations in magnetic susceptibility of top soils along different roads and tracks. The profiles adjacent to main roads (with high traffic density) and near the trucks/tankers parking show higher values of susceptibility. The obtained results also indicate relatively high susceptibility values from leftover-asphalted materials. Refined asphalt (also called bitumen or tar) is a petroleum product, and as such has no magnetic properties. However, if used as a binding material for gravel or sands, the aggregate may give high magnetic susceptibility due to magnetic substances. Reason for such enhanced susceptibility values from the study area may be due to the use of basaltic rocks gravels (magnetically rich) as a mixture. An un-asphalted track road along wadi Aqiq reveals relatively low values of magnetic susceptibility. Residential and commercial areas show medium level of susceptibility. Along narrow roads in agricultural dominant area, the susceptibility values are relatively low, indicating less contamination from vehicular traffics and other anthropogenic activities.

\subsection{Possible Sources of Magnetic Particles in Top Soils}

Magnetic minerals in the urban top soils may be inherited either from parent rocks (lithogenic origin) or from anthropogenic activities as secondary ferromagnetic materials [31] [32] [33] [34]. The lithogenic origin magnetic particles eroded from scattered igneous bodies could be partly responsible for magnetic susceptibility variations in the study area. The location map (Figure 2) indicates exposures of several igneous bodies along different profiles in the study area. In-situ magnetic susceptibility measurements on these parent igneous bodies reveal relatively low values of magnetic susceptibility compared to those from the soil cover. This trend of magnetic susceptibility distribution, therefore, indicates anthropogenic activities as a dominant source of magnetic contamination in top soils compared to lithogenic/pedogenic source. Localized pockets of high susceptibility in the study area are most likely due to traffic-related particulates 
deposition, accumulated in the area immediately after discharging into the environment [29].

Anthropogenic particles in the top soils most likely originate from three sources: 1) emissions from fossil-fuel combustion processes (fly ashes); 2) particles from vehicles, building and road surface (e.g. brake lining dust, exhaust particulates); 3) exotic materials (e.g. metallic fragments, slag and building materials) incorporated into disturbed soil surfaces [35]. In the study area, all these three sources have probably contributed to enhanced magnetic susceptibilities in top soils. However, fly ashes from fossil fuel combustion and other particulates from vehicular traffic caused higher metallic contaminations along major roads compared to narrow farms roads. An improper dumping of building construction materials along with residential waste also created pockets of magnetic particles in top soils. Hundreds of rusted abundant vehicles along different roads in the area also provided magnetic particles to soil cover. High magnetic susceptibility in the trucks and tankers parking area also indicate an enhanced metallic contamination of top soils from such sources. Dumping of asphalted materials at different locations provided some percentage of ferrimagnetic particles to top soils. Widely distributed cans, cloth hangers and other pieces of metallic objects also contributed to metallic contaminations in the area.

\subsection{Heavy Metal Contaminants in Groundwater of Wadi Aqiq}

Some researchers have investigated groundwater resources in the southwestern part of wadi Aqiq (Madinah city) for major, trace and nutrient components [36]. Their quality assessment results revealed $\mathrm{Na}^{+}$and $\mathrm{Cl}^{-}$as main anion and cation in the studied water samples, respectively. The principal component analyses identified three clusters of water samples, reflecting a variation in water quality from one location to another. The authors also found a high level of $\mathrm{NO}_{3}$ in $44 \%$ of groundwater samples, probably from agricultural activities in the area. Moreover, they found high contents of $\mathrm{Pb}, \mathrm{Cd}, \mathrm{Cr}, \mathrm{Ni}, \mathrm{As}$, and $\mathrm{Al}$ in the samples from some locations, which they attributed to unsafe industrial waste disposal in the area. Such high contents of heavy metals in the groundwater confirm their infiltration as contaminants in to the aquifer system.

Similar to southwestern part of wadi Aqiq, the northwestern part (the study area) is also experiencing various types of metallic contaminations from anthropogenic activities. As described in the literature [37], urban anthropogenic particulates get enrichment in toxic trace metals, such as $\mathrm{Fe}, \mathrm{Pb}, \mathrm{Zn}, \mathrm{Ba}, \mathrm{Mn}, \mathrm{Cd}$ and $\mathrm{Cr}$ and magnetic particles. Heavy metal contaminations in top soils and sediments are a chronic environmental issue for public health. Hence, the municipal services in Madinah have to come forward and save this holy wadi from toxic contaminations.

\section{Conclusions and Recommendations}

Preliminary use of magnetic susceptibility as environmental magnetic technique 
divides the study area into different zones of metallic contaminations, giving a way for detailed and integrated investigations in future. Magnetic susceptibility variation from one profile to another indicates various anthropogenic factors for metallic pollutions and contaminations in the area. Relatively low values of magnetic susceptibility from parent igneous rocks support this interpretation. Except the parent igneous rocks, all other sources of contaminations in the soils are anthropogenic in nature. They include vehicular traffic, unsuitable tankers parking, improper waste dumping (such as commercial, residential and building materials), and abandoned rusted cars on the roads.

To fully documents the effects of anthropogenic contaminations in the area, a plan is under consideration to conduct magnetic susceptibility measurements as a function of depth. In addition, geochemical analyses of soils and groundwater samples are also under consideration to support the magnetic results.

Introduction of environmental friendly public transport system for Madinah could help reduce the effects of traffic related contaminations. Secondly, removal of very old vehicles (with high emission levels) from roads could also contribute in lowering air and soil pollutions. Thirdly, a strict rule is required to ban indiscriminate dumping of waste materials (including building demolition/construction, residential, commercial and agricultural) in the area. In case of no action, it will be getting more difficult to protect this important water recharge area from further degradation.

\section{Acknowledgements}

The Deanship of Scientific Research (DSR), Taibah University, Madinah (Saudi Arabia) financially supports this work (Project Number: 1436/6956).

\section{References}

[1] Schibler, L., Boyko, T., Rachwał, M. F., Gajda, B., Höll, S., Jordanova, N., Rösler, W. and Team, M. (2002) Topsoil Magnetic Susceptibility Mapping: Data Reproducibility and Compatibility, Measurement Strategy. Studia Geophysica et Geodaetica, 46, 43-57. https://doi.org/10.1023/A:1019885532390

[2] Mullins, C.E. (1977) Magnetic Susceptibility of Soil and Its Significance in Soils Sciences: A Review. European Journal of Soil Science, 28, 223-246. https://doi.org/10.1111/j.1365-2389.1977.tb02232.x

[3] Thompson, R. and Oldfield, F. (1986) Environmental Magnetism. Allen \& Unwin, London. https://doi.org/10.1007/978-94-011-8036-8

[4] Fine, P., Singer, M.J., La Ven, R., Verosub, K. and Southard R. J. (1989) Role of Pedogenesis in Distribution of Magnetic Susceptibility in Two California Chronosequences. Geoderma, 44, 187-306. https://doi.org/10.1016/0016-7061(89)90037-2

[5] Vassilev, S.V. (1992) Phase Mineralogy Studies of Solid Waste Products from Coal Burning at Some Bulgarian Thermoelectric Power Plants. Fuel, 71, 625-633. https://doi.org/10.1016/0016-2361(92)90164-J

[6] Dekkers, M.J. and Pietersen H.S. (1992) Magnetic Properties of Low-Ca Fly Ash: A Rapid Tool for Fe-Assessment and a Survey for Potentially Hazardous Elements. In: Glasser, F.P., McCarthy, G.J., Young, J.F., Mason, T.O. and Pratt, P.L., Eds., Ad- 
vanced Cementitious Systems-MRS Online Proceeding Library Archive, 245, $37-47$.

[7] Flanders, P.J. (1994) Collection, Measurements and Analysis of Airborne Magnetic Particulates from Pollution in the Environment. Journal of Applied Physics, 75, 5931-5936. https://doi.org/10.1063/1.355518

[8] Georgeaud, V.M., Rochette, P., Ambrosi, J.P., Vandamme, D. and Williamson, D. (1997) Relationship between Heavy Metals and Magnetic Properties in a Large Polluted Catchment: The Etang de Berre (South of France). Physics and Chemistry of the Earth, 22, 211-214. https://doi.org/10.1016/S0079-1946(97)00105-5

[9] Strzyszcz, Z., Magiera, T. and Heller, F. (1996) The Influence of Industrial Emissions on the Magnetic Susceptibility of Soils in Upper Silesia. Studia Geophysica et Geodaetica, 40, 276-286. https://doi.org/10.1007/BF02300743

[10] Hunt, A., Jones, J. and Oldfield, F. (1984) Magnetic Measurements and Heavy Metals in Atmospheric Particulates of Anthropogenic Origin. Science of The Total Environment, 33, 129-139. https://doi.org/10.1016/0048-9697(84)90387-5

[11] Strzyszcz, Z. and Magiera, T. (1998) Magnetic Susceptibility and Heavy Metals Contamination in Soils of Southern Poland. Physics and Chemistry of the Earth, 23, 1127-1131. https://doi.org/10.1016/S0079-1946(98)00140-2

[12] Dearing, J.A., Hay, K.L., Baban, S.M.J., Huddleston, A.S., Wellington, E.M.H. and Loveland, P.J. (1996) Magnetic Susceptibility of Soil: An Evaluation of Conflicting Theories Using a National Data Set. Geophysical Journal International, 127, 728-734. https://doi.org/10.1111/j.1365-246X.1996.tb04051.x

[13] Scholger, R. (1996) Magnetic Susceptibility and Heavy Metal Contamination of Sediments in the River Mur (Styria, Austria). Geologica Carpathica, 47, 191-192.

[14] Scholger, R. (1997) Magnetic Susceptibility as Tools for Mapping of Heavy Metals Contamination of Sediments and Soils: Cast Studies from Styria, Austria. Annales Geophysicae, Part I. Solid Earth Geophysics \& Natural Hazards Supplement I, 15, C105.

[15] Scholger, R. (1998) Heavy Metal Pollution Monitoring by Magnetic Measurements Applied to Sediments of the River Mur (Styria, Austria). European Journal of Environmental and Engineering Geophysics, 3, 25-37.

[16] Hay, K.L., Dearing, J.A., Baban, S.M.J. and Loveland, P.J. (1997) A Preliminary attempt to Identify Atmospherically Derived Pollution Particles in English Topsoils from Magnetic Susceptibility Measurements. Physics and Chemistry of the Earth, 22, 207-210. https://doi.org/10.1016/S0079-1946(97)00104-3

[17] Heller, F., Strzyszcz, Z. and Magiera, T. (1998) Magnetic Record of Industrial Pollution in Forest Soils of Upper Silesia, Poland. Journal of Geophysical Research, 103, 17767-17774. https://doi.org/10.1029/98JB01667

[18] Hoffmann, V., Knab, M. and Appel, E. (1999) Magnetic Susceptibility Mapping of Roadside Pollution. Journal of Geochemical Exploration, 66, 313-326. https://doi.org/10.1016/S0375-6742(99)00014-X

[19] Magiera, T., Strzyszcz, Z., Kapicka, A. and Petrovsky, E. (2006) Discrimination of Lithogenic and Anthropogenic Influences on Topsoil Magnetic Susceptibility in Central Europe. Geoderma, 130, 299-311. https://doi.org/10.1016/j.geoderma.2005.02.002

[20] Lu, S.G., Bai, S.Q. and Xue, Q.F. (2007) Magnetic Properties as Indicators of Heavy Metals Pollution in Urban Topsoils: A Case Study from the City of Luoyang, China. Geophysical Journal International, 171, 568-580. https://doi.org/10.1111/j.1365-246X.2007.03545.x 
[21] Zhang, C., Qiao, Q., Piper, J.D.A. and Huang, B. (2011) Assessment of Heavy Metal Pollution from a Fe-Smelting Plant in Urban River Sediments Using Environmental Magnetic and Geochemical Methods. Environmental Pollution, 159, 3057-3070. https://doi.org/10.1016/j.envpol.2011.04.006

[22] Dlouha, S., Petrovsky, E., Kapicka, A., Boruvka L., Ash, C. and Drabek, O. (2013) Investigation of Polluted Alluvial Soils by Magnetic Susceptibility Methods: A Case Study of the Litavka River. Soil and Water Research, 8, 151-157. https://doi.org/10.17221/14/2013-SWR

[23] Wang, B., Xia, D.S., Yu, Y., Jia, J. and Xu, S.J. (2014) Detection and Differentiation of Pollution in Urban Surface Soils Using Magnetic Properties in Arid and Semi-Arid Regions of Northwestern China. Environmental Pollution, 184, 335-346. https://doi.org/10.1016/j.envpol.2013.08.024

[24] Aydin, A. and Akyol, E. (2015) Observing Urban Soil Pollution Using Magnetic Susceptibility. International Journal of Environmental Research, 9, 295-302.

[25] Bamousa, A.O., Matar, S.S., Daoudi, M. and Al-Doaan, M.I. (2012) Structural and Geomorphic Features Accommodating Groundwater of Al-Madinah City, Saudi Arabia. Arabian Journal of Geosciences, 6, 3127-3132. https://doi.org/10.1007/s12517-012-0574-x

[26] George, M. and Shorbaji, H. (1987) Explanatory Notes to the Hydrogeological and Hydrochemical Maps of the Al Madinah Quadrangle. Sheet 24D KDS Open-File Rep BRGM-OF-07-23, Ministry of Petroleum and Mineral Resources, KSA.

[27] Bokhari, A.Y. and Khan, M.Z.A. (1992) Deterministic Modeling of Al-Madinah Al-Munawarah Groundwater Quality Using Lumped Parameter Approach. Journal of King Abdulaziz University, Earth Sciences, 5, 89-107. https://doi.org/10.4197/Ear.5-1.5

[28] Al-Shaibani, A.M, Lloyd, J.W., Abokhodair, A.A. and Alahmari, A. (2007) Hydrogeological and Quantitative Groundwater Assessment of the Basaltic Aquifer, Northern Harrat Rahat, Saudi Arabia. The Arab Gulf Journal of Scientific Research, $25,39-49$.

[29] Petrovsky, E. and Ellwood, B.B. (1999) Magnetic Monitoring of Air-, Land and Water Pollution. In: Maher, B.A. and Thompson, R., Eds., Quaternary Climates, Environments and Magnetism, Cambridge University Press, Cambridge, 279-322. https://doi.org/10.1017/CBO9780511535635.009

[30] Gautam, P., Blaha, U. and Appel, E. (2005a) Integration of Magnetism and Heavy Metal Chemistry of Soils to Quantify the Environmental Pollution in Kathmandu, Nepal. Island Arc, 14, 424-435. https://doi.org/10.1111/j.1440-1738.2005.00496.x

[31] Magiera, T. and Strzyszcz, Z. (2000) Ferrimagnetic Minerals of Anthropogenic Origin in Soils of Some Polish National Parks. Water, Air, \& Soil Pollution, 124, 37-48. https://doi.org/10.1023/A:1005258125921

[32] Yang, T., Liu, Q., Chan, L. and Cao, G. (2007) Magnetic Investigation of Heavy Metals Contamination in Urban Top Soils around the East Lake, Wuhan, China. Geophysical Journal International, 171, 603-612. https://doi.org/10.1111/j.1365-246X.2007.03558.x

[33] Boyko, T., Scholger, R. and Stanjek, H. (2004) Topsoil Magnetic Susceptibility Mapping as a Tool for Pollution Monitoring: Repeatability of in Situ Measurements. Journal of Applied Geophysics, 55, 249-259.

https://doi.org/10.1016/j.jappgeo.2004.01.002

[34] Hanesch, M. and Scholger, R. (2005) The Influence of Soil Type on the Magnetic Susceptibility Measured throughout Profiles. Geophysical Journal International, 
161, 50-56. https://doi.org/10.1111/j.1365-246X.2005.02577.x

[35] Lu, S.G. and Bai, S.Q. (2006) Study on the Correlation of Magnetic Properties and Heavy Metals Content in Urban Soils of Hangzhou City, China. Journal of Applied Geophysics, 60, 1-12. https://doi.org/10.1016/j.jappgeo.2005.11.002

[36] Bamousa, A.O. and Magdy, E.M. (2016) Groundwater Characterization, Quality Assessment, and Sources of Pollution in Madinah, Saudi Arabia. Arabian Journal of Geosciences, 9, 536. https://doi.org/10.1007/s12517-016-2554-z

[37] Maher, B. (2009) Rain and Dust: Magnetic Records of Climate and Pollution. Elements, 5, 229-234. https://doi.org/10.2113/gselements.5.4.229 